\title{
A Study on the Experience of Children's Participatory Playground Design: Based on the Experiences of Architects Who Participated in the Protect the Playground Project by Save the Children
}

\author{
Hyun-Sun Park ${ }^{1}$ and Soongyu Kim ${ }^{2}$ \\ ${ }^{1}$ Dept. of Social Welfare, Sejong University, South Korea \\ ${ }^{2}$ Dept. of Social Welfare, Jeonbuk National University, South Korea \\ 1hyunpark@sejong.ac.kr, ${ }^{2}$ soongyu@jbnu.ac.kr
}

\begin{abstract}
This study examines the experiences of operating a children's participation workshop by architects for Protect the Playground project, a play space creation project funded by Save the Children. This study discusses the development of the children's participation workshop as a tool for the realization of children's rights. To this end, four architects who participated in the design and creation of the play space project for Save the Children were selected and In-Depth Interviews (IDI) with them were conducted by the researchers. The consensus among the interviewees was that the children's participation workshop allowed children to have a sense of ownership of their play space and also highlighted to the architects their responsibilities to the children involved. Although there were difficulties in conducting the workshop due to internal and external challenges associated with the children's involvement, it was found that the participation of the children and their resulting opinions played an essential role in completing the play space design and led to changes in the perception of the adults involved in the projects. The researchers found that the children's participation workshop provided opportunities for adults to recognize children's rights and that it had a meaningful impact on the architects, teachers, parents, local residents, and everyone involved in this project. From the results of this study the researchers believe it is necessary to place more emphasis on children's participation workshops in the creation of play space projects, and that the children's participation workshop should be used as a model when implementing child-related policies in other areas in order to better represent children and safeguard their rights.
\end{abstract}

Keywords: Save the children, Creating play space project, Children's participation workshop, Child rights, Architect

\section{Introduction}

In recent years, amid rising social interest in children's participation, relevant research conditions for children's participation are actively progressing. The improvement of research conditions related to children's participation is made as part of an effort to reflect the opinions of children in projects and programs - this is related to the creation and certification of children-friendly cities. Previous studies have shown that children's participation is favorable for the growth and change of children, and it has been reported to have a real positive effect

Article history:

Received (September 18, 2020), Review Result (October 22, 2020), Accepted (November 29, 2020) 
$[5][6][7][8][9]$. As such, children's participation is emphasized and is emerging as a social issue. However, children's involvement has been passive in the majority of the time. This is because practical difficulties such as children's developmental characteristics, work efficiency, and lack of experience coexist. However, if the children's participation as a children's right can be realized properly, it will not only reduce behaviors that infringe on children's rights by emphasizing the vulnerability of children but also contribute to the recognition and respect of children as members of society. How can child participation be implemented? Regarding this question, it is necessary to review Save the Children's creating play space project. Save the Children has been constructing various types of urban and rural playgrounds and improvement projects since 2014 as part of the campaign to protect the playground [3]. Save the Children's creating play space project, the importance of play and favorable developments were confirmed [1][5]. In particular, Park Hyeon-seon et al. evaluated all types of creating playspace projects conducted by Save the Children from 2014 in a multi-faceted manner to verify the process characteristics and performance of the project comprehensively.

Therefore, this study focuses on the children's participation workshop in the process [Figure 1] of creating play space projects concerning children's participation and the process, meaning, and effects of the involvement of children are examined through the experience of architects operating the workshops. Through the examining process, the direction of development of the children's participation workshop and children's rights is to be discussed.

\begin{tabular}{|c|c|c|c|c|c|c|c|c|c|c|c|c|}
\hline $\begin{array}{l}\text { open } \\
\text { recruitment }\end{array}$ & $\Rightarrow$ & screening & $\Rightarrow$ & $\begin{array}{l}\text { architect } \\
\text { selection }\end{array}$ & $\Rightarrow$ & $\begin{array}{l}\text { business } \\
\text { agreement }\end{array}$ & $\Rightarrow$ & workshop & $\Rightarrow$ & construction & $\Rightarrow$ & $\begin{array}{l}\text { opening } \\
\text { ceremony }\end{array}$ \\
\hline
\end{tabular}

Figure 1. Process of creating play space

\section{Research method}

\subsection{Research methodology}

This study discusses the direction of the children's participation as a tool for the realization of children's rights. To this end, four architects who participated in the design and creation of the play space project for Save the Children. In order to explore the experience of children's participation from the perspective of the research subjects, a qualitative method is appropriate, and in-depth interviews are conducted through questionnaire were deemed suitable for the research purpose.

\subsection{Study participants}

The participants in the in-depth interview survey are four architects who have previously participated in several creating play space projects conducted by Save the Children, such as school playground environment improvement, rural playground support project, public community child center support since 2014. Meanwhile, research participants were limited to those who had participated in Save the Children projects more than twice.

\subsection{Data collection and analysis method}

In order to collect data, this study conducted an in-depth interview (IDI: In-Depth Interview) for study participants from July to August 2019. Study participants were informed about the in-depth interview survey and participation observation before any study was 
conducted. After receiving consent to participate in the study from participants who expressed their willingness to participate, an in-depth interview was carried out over an hour and a half to two hours. Also, the recorded in-depth interview data were converted into written data and the contents were analyzed.

Table 1. Characteristics of the participants

\begin{tabular}{|c|c|c|c|}
\hline Participant & Sex & Age & Project Participation Duration \\
\hline A & Male & 47 & $2017 \sim$ Present \\
\hline B & Male & 38 & $2017 \sim$ Present \\
\hline C & Female & 44 & $2017 \sim$ Present \\
\hline D & Female & 43 & $2017 \sim$ Present \\
\hline
\end{tabular}

\subsection{Research rigor and ethical considerations}

This study initiated having the goal of putting down the understanding and prejudice of researchers to increase the rigor of the pressing children related issues. Researchers proceeded from the process of selecting a research participant to the interview process, and to share and check the interview results with the study participants. The results of the study promised that they would never be used for any other purpose other than this study; we thoroughly explained the voluntariness, rights guarantee, confidentiality, and risks and benefits of participating in the study [8].

\section{Results}

\subsection{Experience of participating in the play space creation project}

Consider the experience of the research participants who are involved in creating play space projects; research participant A participated in a total of four creating play space projects from 2017 to 2019. For example, public community children's center project No. 1, and in 2019, an urban playground project was in progress. Research Participant B worked with Save the Children in seven projects and is currently conducting three projects this year. Specifically, he participated in the public community children's center project three times, and the rural playground project twice. In 2019, he also participated in one general community children's center project and two school playground projects. Research participant C continued to participate in the school playground project since Sheung Elementary School and conducted a total of four projects. Research participant D has participated in the project since 2017 and had been participating in eight projects so far. Specifically, in 2017, she participated in one school playground improvement project and one rural playground project. In 2018, she participated in three school playground improvement projects, and a year later, two creating play space projects and a public type. She was participating in one local children's center project.

\subsection{Experience of running the child participation workshop while creating the play space}

It was confirmed that the workshop, which consists of children's participation, is a place of activity where children's thoughts can be embodied, as well as an opportunity to develop affection and interest in the play space. Also, because of this importance, it was found that I 
felt a sense of responsibility as an architect and put my best effort into administering the workshop effectively. However, factors that make it challenging to conduct the workshop are due to the unfamiliar social atmosphere of child participation, the difficulty of drawing commonalities from various children, the process of coordinating the opinions of children with other adults, and the confusion about whether the workshop is the job of an architect. Despite these difficulties, experiencing children happily participated in various activities designed in the workshop had helped to complete the study design and led to a change in the perception of many adults.

\subsubsection{Children have a sense of ownership}

Children's participation workshops consisted of active participation of children through discussions, questions, and explanations. Such activities became an opportunity for children to know that they and their friends may have different opinions about workshop activities.

\subsubsection{Assists in understanding children}

Participants in the study designing a children's play space were acquiring the children's needs through children's participation workshops. Accordingly, when conducting the workshop, the participants of the study respected the thoughts and opinions of the children. They tried to draw out the opinions of the children as much as possible by using various expression methods. Also, the children's opinions and other design results were sufficiently explained to the child, and consent was sought.

\subsubsection{Accountability as an architect}

Participants of the study considered it essential to appropriately reflect the children's various ideas expressed through the workshop in the design. Therefore, it was attempted to understand the children's thoughts as accurately as possible through the workshop. It was pointed out that the experience of the workshop with the children and the time spent with the children in the field is recognized as necessary. In addition, we saw that the opportunity to share our workshop experiences with architects could be helpful in designing as well. As such, the study participants are trying to understand the children's thoughts accurately and reflect them in the design, which was understood as a responsibility as an architectural expert.

\subsubsection{Feeling the difficulty of conducting the workshop}

Participants in the study were receiving help from various aspects, such as understanding children's thoughts and designing based on them through child participation workshops. However, it was found that the workshop was not smooth due to internal and external factors. First, they pointed out the policies respect the position of managers or budget providers, not users, especially the social aspects in which children's opinions are hardly reflected even though the place is exclusively for children. And these difficulties coexisted in the creating play space project according to the budget subject. In addition, it was difficult to operate the workshop due to the different conditions and characteristics of the participating children, such as the characteristics of rural and urban children and the developmental difference between the high and low grades. On the other hand, it was found that the participants of the study had a burden on the operation of the workshop due to internal factors such as anxiety about whether their role in the workshops was well justified mostly due to their lack of experience, 
and the burden of preparation. Due to these internal and external factors, it was found that the participants of the study had difficulty in conducting the workshop.

\subsubsection{Acting force of overcoming difficulties}

Although the participants of the study feel it is difficult to conduct the workshop due to internal and external factors, children's opinions by themselves can be conveyed to adults by embedding children's opinions in the design and maintain the existing design by emphasizing their opinions. In addition, the development of the staff through the accumulation of experience in the workshop and the change in adult perceptions obtained in the process of overcoming conflicts and difficulties have become a driving force for the research participants to continue this project. It is noticeable that the above contents serve as a force for the research participants to continue running the workshop despite various difficulties.

\subsubsection{Suggestions for new attempts and directions for the development of workshop management}

Participants in the study were contemplating new attempts and improvements related to effective workshop management based on their practical experience in conducting workshops. The know-how of the workshop operation was evolving into a more developed form, such as using a play expert before the workshop to form a relationship with the children, or trying to draw out potential children's needs and opinions by using various play materials in the workshop. In addition, it was suggested to run the workshop in the form of a camp or use children of the same age, and to link additional child participation activities after the playground was completed. Above all, we emphasized that the number of workshops should be increased, and at the same time, cost support for human resources is also needed to keep the workshops running smoothly.

\section{Conclusion and implications}

This study examines the experience of operating a children participation workshop for architects who were selected and designed for creating play space projects conducted by Save the Children. It then suggests the direction of development of the child participation workshop. In addition, we discussed the approach of child participation to realize children's rights from a macro perspective. To this end, four architects who had experience in creating play space projects were selected as participants in the study, and an in-depth interview was conducted.

Based on these results, we would like to discuss the development direction of the child participation workshop and the ways to expand child participation rooted in children's rights. First, I would like to discuss the development direction of child participation workshops in the play space creation project. In terms of designing spaces for children, the study participants emphasized the need to strengthen workshops to understand children and to confirm their opinions. Accordingly, the playground support organization must propose various types of workshops that can maximize children's participation and expand the budget for workshop support concerning operation. In addition, it is necessary to additionally include seminars and conferences where architects can share their experiences in the play space creation project process, and guidelines for the operation of programs based on child participation after the completion of the playground business are also required. Second, based on children's rights, we will discuss ways to expand child participation. Recently, 
discussions have been actively conducted among local governments on the establishment of child-friendly spaces, legal system establishment, child participation guarantees, recognition of children's rights, and advocacy activities for the creation or certification of a child-friendly city organized by UNICEF. Of these, guaranteeing children's participation can be said to be one of the most important and essential activities in terms of ensuring children's rights [2]. Accordingly, many local governments that operate child-friendly cities are carrying out various activities for child participation. However, still, only a few children participate in child participation activities or make a final decision by asking children only their opinions as a formality, and all decisions are made by adults [5]. In this respect, the children's participation workshop, which is being effected in the play space creation project, provides a direction on how child participation should be done. In other words, the Children Participation Workshop conducts various activities centered on the children and allows the opinions suggested by the child to be realized can be an exemplary model for dealing with other child-related issues or policies.

As this study was conducted with architects who have experience in participating in children's participatory playground projects, a direction for future studies would be to conduct child participation studies with children, focusing on their experiences and perceptions of these kinds of projects.

\section{References}

[1] Myungwoo Institute of Clinical Psychology, "Save the Children's project result report: Helping our schools play well," Save the Children, (2016)

[2] Se-kyung park. "Child rights and child-friendly cites: Focusing on the experiences of major Europena cities," Health and Welfare Forum, pp.62-72, (2016)

[3] Hyun-Sun Park., Hyunsuk Jwa., Se-Won Kim., Soongyu Kim., Minyeong Song., and Soim Lee., "Children and communities where play has changed: An evaluation study of save the playground project by save the children," Save the Children, (2020)

[4] Save the Children. "Helping our schools play well," Save the Children, (2018)

[5] Eun-Chan Oh., and Ick-Joong Chung, "Participation experiences of children: Ranked children's learning of how to live together," Journal of School Social Work, vol.32, pp.217-246, (2015)

[6] Jeongwoong Cheon, "The need and value of youth participation for a good society," Journal of Adolescent Behavior Science, vol.3, pp.97-120, (1998)

[7] Vis, S.A., Strandbu, A., Holtan, A. and Thomas, N., "Participation and health-a research review of child participation in planning and decision-making," Child and Family Social Work, vol.16, pp.325-335, (2011)

[8] Padgett, D. K., "Qualitative methods in social work research: challenges and rewards," (1998)

[9] Ji-Hye Lee. "Children's participation in decision-making at home," Journal of Korean Council for children \& Rights, vol.24, pp.547-584, (2020) 


\section{Authors}

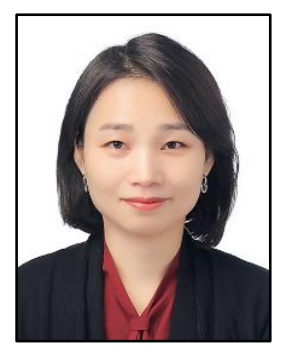

Dr. Hyun-Sun, Park, PhD

Professor, Dept. of Social Welfare, Sejong University, South Korea

Main filed of Interest: Child \& Youth Welfare, Children's play Right

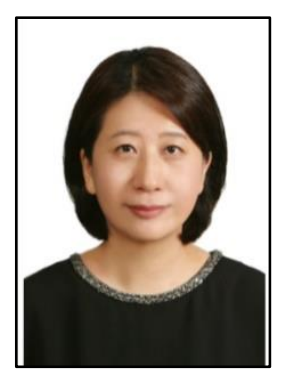

Dr. Soongyu, Kim, PhD

Professor, Dept. of Social Welfare, Jeonbuk National University, South Korea

Main filed of Interest: Child \& Youth Welfare, School Social work 
A Study on the Experience of Children's Participatory Playground Design: Based on the Experiences of Architects Who Participated in the Protect the Playground Project by Save the Children

This page is empty by intention. 